\title{
PROJETO ATLAS LINGUÍSTICO DO BRASIL: ANTECEDENTES E ESTÁGIO ATUAL
}

\author{
Suzana Alice CARDOSO* \\ Jacyra Andrade MOTA**
}

- RESUMO: Neste artigo, trata-se do Projeto Atlas Linguístico do Brasil, destacando-se os antecedentes que, na história da Geolinguística brasileira, explicam o seu surgimento, em 1996, por ocasião do Seminário Caminhos e Perspectivas para a Geolinguística Brasileira, realizado na Universidade Federal da Bahia, com a participação de pesquisadores da área, particularmente de autores de atlas publicados e de atlas em andamento. Apresentam-se informações sobre a sua estrutura, seus objetivos, como vem se desenvolvendo a pesquisa de campo, o estágio em que se encontra, atualmente - com 92,8\% de localidades pesquisadas -, e resultados que as análises preliminares têm revelado. Destacam-se dois aspectos da sua organização: a realização de reuniões sistemáticas do Comitê Nacional que coordena o Projeto (a última das quais, a de número XXXIV, se realizou em fevereiro de 2012) e workshops para discussão, acompanhamento do trabalho e formação de inquiridores e de pesquisadores auxiliares. Do ponto de vista metodológico, o projeto se insere na geolinguística pluridimensional contemporânea, priorizando não só a variação diatópica, mas também a variação diageracional, diagenérica e diastrática.

- PALAVRAS-CHAVE:Atlas Linguístico do Brasil. Geolinguística. Diatopia. Variação linguística.

\section{Introdução}

O Projeto Atlas Linguístico do Brasil (Projeto ALiB) constitui-se na primeira tentativa, em nível nacional, de descrição do português brasileiro com base em dados coletados, in loco, nas diversas regiões geográficas, a partir da investigação em uma rede de pontos que se estende do Oiapoque (ponto 001) ao Chuí (ponto 250). Trata-se, portanto, de um projeto que se desenvolve no campo da variação linguística, mais especificamente no campo da Dialetologia e com base na Geolinguística, caminho metodológico que se ocupa da cartografia dos fatos de língua, cuja produção de maior relevância se consubstancia nos atlas linguísticos. Dá curso a uma tendência dos estudos da linguagem que, iniciada na Europa com

\footnotetext{
* UFBA - Universidade Federal da Bahia. Instituto de Letras - Departamento de Letras Vernáculas. Salvador Bahia - Brasil. 40170-290 - suzalice@ufba.br

** UFBA - Universidade Federal da Bahia. Instituto de Letras - Departamento de Letras Vernáculas. Salvador Bahia - Brasil. 40170-290 - jacymota@ufba.br
} 
o Atlas Linguistique de la France (1902-1910), obra de Jules Gilliéron, se expande e se diversifica no que concerne à abrangência da área considerada — atlas regionais, nacionais, de família de línguas e de um continente.

O Projeto ALiB responde a um desejo expresso por filólogos e linguistas brasileiros e enfaticamente reivindicado por Nascentes (1958, p.7) que, nas suas Bases para a elaboração do atlas linguístico do Brasil (1958), assinala a importância dos atlas linguísticos: "[...] Depois de Gilliéron, o fundador da geografia linguística, nenhum verdadeiro estudioso da filologia nega o valor dos atlas linguísticos nem o seu caráter de indispensáveis."

Com tal entendimento, apresenta-se, neste artigo, uma visão do Projeto ALiB, trazendo informações sobre os antecedentes, os objetivos e a metodologia seguida e fornecendo uma visão do estágio atual do seu desenvolvimento.

\section{Antecedentes do projeto ALiB}

A partir da segunda metade do século XX, os pesquisadores brasileiros começam a ressaltar a importância e a necessidade de realizar-se um atlas linguístico nacional, obra que colocaria o país junto a alguns países europeus, que já contavam com trabalhos dessa natureza.

Com relação à língua portuguesa, Silva Neto (1957), em "breve comunicação", apresentada no 10. Colloquium Internacional de Estudos Luso-Brasileiros, realizado, em 1950, em Washington, refere-se ao fato de ainda não se haver realizado, àquela época, o Atlas Lingüístico-Etnográfico de Portugal e Ilhas, o que considera "uma das mais prementes necessidades da Filologia Portuguêsa" e "obra de capitalíssima importância, que virá revolucionar os nossos conhecimentos de Filologia Portuguêsa e facilitar os nossos incipientes estudos acerca dos falares brasileiros". Ressalta a urgência desse atlas, inspirando-se nas palavras de Meillet a respeito do Atlas Ítalo-Suíço, publicado entre 1928 e 1940, como se lê no trecho:

É preciso ter no espírito, como um aguilhão a apressar-nos, aquelas palavras de Antoine Meillet'. " "Qui a manié un Atlas comme celui-ci (Atlas Ítalo-Suíço) a l'impression qu'une linguistique que non dispose pas d'un pareil instrument est infirme." (SILVA NETO, 1957, p.9).

Entendendo a justa valia de um atlas linguístico e numa demonstração clara do interesse pela realização do atlas linguístico do Brasil, o Governo Brasileiro, ao promulgar o Decreto no. 30.643, de 20 de março de 1952, fixa como um dos principais objetivos da Comissão de Filologia da então criada Casa de Rui Barbosa

Quem teve em suas mãos um atlas linguístico como este (Atlas Ítalo-Suíço) fica com a impressão de que uma linguística que não dispõe de um instrumento similar não tem valia. 
a elaboração de um atlas linguístico do Brasil — " [...] sendo sua finalidade principal a elaboração do Atlas Lingüístico do Brasil" (Art. $3^{\circ}$ ) —, disposição que vem a ser regulamentada pela Portaria n. ${ }^{\circ} 536$, de 26 de maio do mesmo ano.

No entanto, apesar desse pronunciamento favorável por parte do governo brasileiro e do esforço de alguns pesquisadores (notadamente Serafim da Silva Neto, Celso Cunha, Antenor Nascentes e Nelson Rossi) em prol de obra de tal natureza, inúmeras dificuldades impediram a sua realização, o que levou Silva Neto e Celso Cunha a apresentarem, em 1957, no III Colloquium de estudos lusobrasileiros, em Lisboa, a proposta de Atlas Linguístico-Etnográfico do Brasil por regiões, com a divisão do país, de acordo com Silva Neto, em sete áreas culturais, como se lê no parágrafo inicial do texto:

É tarefa das mais urgentes a organização de um Atlas LinguísticoEtnográfico do Brasil, obra que irá tornar possível, pela primeira vez, uma visão de conjunto do desenvolvimento e do estado actual da língua portuguesa na América. (CUNHA; SILVA NETO, 1960, p.405).

Nascentes (1958, p.8), nas Bases para a elaboração do Atlas Lingüístico do Brasil, retoma essa proposta, especificando:

Temos de dividir o país em regiões, cada uma com o seu superintendente, ficando os superintendentes sob a direção de um técnico, havendo um órgão central supervisor, a Comissão de Filologia.

Começaremos pela divisão em regiões.

[...] o professor Serafim da Silva Neto [...] dividiu o nosso país nas seguintes áreas culturais:

1. Amazônia (Acre, Amazonas, Rio Branco, Pará e Amapá);

2. Nordeste Litoral (Maranhão, Piauí, Ceará, Rio Grande do Norte, Fernando de Noronha, Paraíba, Pernambuco, Alagoas e Sergipe);

3. Nordeste Mediterrâneo (Maranhão, Piauí, Ceará, Paraíba, Pernambuco, Alagoas e Bahia);

4. Planalto Central (Minas Gerais e sudoeste da Bahia);

5. Centro-Oeste (Goiás e Mato Grosso);

6. Centro-Leste (Rio de Janeiro, Distrito Federal, Espírito Santo, Sul de Minas e São Paulo);

7. Sul (Paraná, Santa Catarina e Rio Grande do Sul).

Devemos começar pelos atlas de regiões onde já tenham sido feitas sondagens.

Estas regiões são: a Amazônia, a Bahia e o Rio Grande do Sul. 
No seu objetivo de delinear os caminhos da execução de obra como essa, apresenta, a seguir, como sugestão, "[...] um questionário típico, de caráter geral [...] e uma lista de pontos em que devem ser feitos os inquéritos" (NASCENTES, 1958, p.8).

A decisão de se elaborarem atlas regionais, embora não seguida dentro do esquema previsto por Nascentes, inspirou inúmeras pesquisas, dando origem a diversos atlas, o primeiro dos quais, o Atlas Prévio dos Falares Baianos ${ }^{2}$ idealizado por Nelson Rossi e realizado com a colaboração de Dinah Isensee e Carlota Ferreira, publicado em 1963 — inaugura a Geolinguística brasileira.

Em 1996, quando se inicia o Projeto Atlas Linguístico do Brasil (ALiB), já estavam publicados mais quatro atlas regionais — o Esboço de um Atlas Lingüístico de Minas Gerais (EALMG), em 1977; o Atlas Lingüístico da Paraíba (ALPB), em 1984, o Atlas Lingüístico de Sergipe (ALS), em 1987, e o Atlas Lingüístico do Paraná (ALPR), em 1994, encontrando-se, em andamento, o Atlas Lingüístico-Etnográfico da Região Sul (ALERS), que seria publicado em 200233.

\section{Projeto Atlas Linguístico do Brasil (ALiB)}

Em consonância com esse percurso dos estudos dialetais brasileiros e por iniciativa de um grupo de pesquisadores ligados à área da Dialetologia/ Sociolinguística, é retomada a ideia de elaboração de um atlas linguístico nacional, no tocante à língua portuguesa, por ocasião do Seminário Caminhos e Perspectivas para a Geolinguística no Brasil, ocorrido em novembro de 1996, no Instituto de Letras da Universidade Federal da Bahia, momento em que se constituiu um Comitê Nacional para coordená-lo.

Acatada a iniciativa, compôs-se o Comitê Nacional que, no seu primeiro momento, ficou constituído pelos autores dos atlas regionais até então publicados - Suzana Alice Cardoso (escolhida como Presidente do Comitê), Jacyra Andrade Mota (Diretora Executiva), ambas da UFBA, Maria do Socorro de Aragão (UFPB/ UFCE), Vanderci de Andrade Aguilera (UEL) e Mário Roberto Lobuglio Zágari (UFMG) - e por um representante dos atlas em andamento - Walter Koch (UFRGS) - como Diretores Científicos. Em 2002, com a publicação do ALERS, Walter Koch passa a figurar como autor de atlas publicado, abrindo espaço para a inclusão de Aparecida Negri Isquerdo, como representante dos atlas em andamento. Com o falecimento de Walter Koch (em 2008) e de Mário Roberto Lobuglio Zágari (em 2010), passam a integrar também o Comitê Nacional Cleo Altenhofen (UFRGS), Felício Margotti (UFSC) e Ana Paula Rocha (UFOP).

2 Confira: ROSSI; CALLOU; FERREIRA (1963).

3 Confira: RIBEIRO, et al. (1977); ARAGÃO; MENEZES (1984); FERREIRA, et al., (1987); AGUILERA (1994); KOCH, et al. (2002). 


\section{Objetivos}

O Projeto ALiB, que vem ser assumido por esse grupo de dialetólogos, tem ao lado do objetivo geral de fornecer dados empíricos, sistematicamente recolhidos e analisados, para o conhecimento do português do Brasil, os seguintes objetivos específicos:

1. Descrever a realidade lingüística do Brasil, no que tange à língua portuguesa, com enfoque prioritário na identificação das diferenças diatópicas (fônicas, morfossintáticas, léxico-semânticas e prosódicas) consideradas na perspectiva da Geolinguística.

2. Estabelecer isoglossas com vistas a traçar a divisão dialetal do Brasil, tornando evidentes as diferenças regionais através de resultados cartografados em mapas lingüísticos e de estudos interpretativos de fenômenos considerados.

3. Examinar os dados coletados na perspectiva de sua interface com outros ramos do conhecimento - história, sociologia, antropologia, etc. — de modo a poder contribuir para fundamentar e definir posições teóricas sobre a natureza da implantação e desenvolvimento da língua portuguesa no Brasil.

4. Oferecer, aos interessados nos estudos lingüísticos, um considerável volume de dados que permita aos lexicógrafos aprimorarem os dicionários, ampliando o campo de informações; aos gramáticos atualizarem as informações com base na realidade documentada pela pesquisa empírica; aos autores de livros didáticos adequarem a sua produção à realidade cultural de cada região; aos professores aprofundar o conhecimento da realidade linguística, refletindo sobre as variantes de que se reveste a língua portuguesa no Brasil e, conseqüentemente, encontrando meios de, sem desprestigiar os seus dialetos de origem, levar os estudantes ao domínio de uma variante tida como culta.

5. Contribuir para o entendimento da língua portuguesa no Brasil como instrumento social de comunicação diversificado, possuidor de várias normas de uso, mas dotado de uma unidade sistêmica (COMITÊ NACIONAL, 2001, p.16).

Definidos os objetivos, implementou-se a metodologia, que vai encontrar suas bases na Dialetologia Pluridimensional contemporânea, que, além de priorizar a dimensão diatópica, vai se fazer valer dos avanços que a nova realidade dos espaços e de sua ocupação imprimiram à metodologia dos estudos dialetais, considerando também outras dimensões, como a diageracional, diagenérica, diastrática, diafásica. 


\section{Metodologia}

Assim, ao adotar os parâmetros da Geolinguística pluridimensional contemporânea, o Projeto ALiB filia-se a uma nova concepção nos estudos geolinguísticos, assim identificada por Thun (2000, p.408):

La nouvelle géolinguistique se caractérise par l'élargissement de son champ d'observation et par un travail en profondeur plus poussé. Elle passe de l'analyse de la superficie, constituée par la dimension diatopique, à celle de l'espace linguistique formé par la prise en considération de variables comme la dimension diastratique, diaphasique ou d'autres.

Elle n'emploie plus toute son énergie à la recherche du dialecte pur rural mais elle entre également dans les villes, elle analyse des langues régionales, focalise des situations de contact, questionne aussi des gens démographiquement mobiles. ${ }^{4}$

A "nouvelle géolinguistique", a que se refere Thun, busca unir ao princípio da diatopia, pelo qual se vem regendo a Dialetologia desde os seus primórdios, princípios sociolinguísticos que, juntando-se ao primeiro, vão ensejar cartas linguísticas ${ }^{5}$ que permitem ao leitor não só saber onde se diz tal coisa, mas que tipo de falante - homem-mulher, jovem-velho, escolarizado-não escolarizado — é responsável por aquele enunciado.

Para alcançar a abrangência desejada, de acordo os parâmetros metodológicos da Geolinguística Pluridimensional, o Projeto ALiB insere, ao lado da pesquisa da variação diatópica, também a de outras dimensões variacionais, como a diageracional, a diagenérica, a diastrática, a diafásica e a diarreferencial.

Do ponto de vista diatópico, a rede, constituída de 250 pontos, distribui-se, geograficamente, por todo o território nacional, levando em conta a densidade demográfica de cada região e de cada Estado, com os ajustes necessários nos casos de áreas com densidade muito baixa, como a região norte e centro-oeste, ou demasiadamente elevada, como na região sudeste, principalmente em São Paulo. E, na seleção das localidades, além da distribuição espacial, consideram-se a importância de cada uma delas na região e no Estado e dados de sua formação, além de limites interestaduais e internacionais. Incluem-se cidades de grande e

4 A nova Geolinguística se caracteriza pela ampliação de seu campo de observação e por um trabalho de maior profundidade. Passa da análise da superfície, constituída pela dimensão diatópica, para a do espaço linguístico voltado para a consideração de outras dimensões como a diastrática e a diafásica.

Ela não emprega mais toda a sua energia na busca do dialeto rural puro, mas entra igualmente nas cidades, analisa os dialetos regionais, focaliza situações de contato, questiona também os grupos demograficamente móveis.

5 Mister se faz esclarecer que a Dialetologia monodimensional, nada obstante priorizar na cartografia os dados diatópicos, considera, na seleção de informantes, falantes diferenciados em idade, escolaridade e de sexos distintos. 
médio porte, inclusive as capitais de Estado — à exceção do Distrito Federal e de Palmas, no Tocantins, cidades de formação relativamente recente nas quais ainda não se pode dispor de três gerações nascidas e criadas na área e com idade requerida para a seleção de informantes.

Para atender à variação social, os informantes, em número de quatro em cada ponto - exceto nas capitais de Estado, onde são oito - estratificam-se quanto ao gênero - quinhentos e cinquenta homens e quinhentas e cinquenta mulheres —, à faixa etária — a primeira de 18 a 30 anos e a segunda, de 50 a 65 anos - e, nas capitais, ao nível de escolaridade - fundamental e universitário.

De acordo com a metodologia geolinguística, o informante deve ser natural da localidade, onde deve ter passado $2 / 3$ de sua vida e filho de pessoas naturais da mesma área linguística. Os afastamentos não devem coincidir com os primeiros anos de vida do indivíduo (fase de aquisição da linguagem), nem com os anos imediatamente anteriores àquele em que se realiza o inquérito.

A variação diafásica ou estilística pode ser analisada a partir das respostas aos questionários previamente elaborados para a constituição do corpus (COMITÊ NACIONAL, 2001), confrontando-se os registros de fala mais monitorada, nas respostas monovocabulares, obtidas através de perguntas diretas, aos de elocuções mais espontâneas, surgidas por iniciativa do próprio informante, em comentários livres, ou por sugestão do inquiridor, na parte final da entrevista.

Para a análise do que se identifica como variação diarreferencial, incluem-se seis questões de natureza metalinguística, e se apresenta, finalizando a aplicação dos questionários, um pequeno texto para leitura, com vistas a ampliar o espectro das considerações diafásicas.

Os questionários, que passam a ser descritos, indicam um dos caminhos adotados - a diversidade na interrogação - para caminhar-se ao encontro da amplitude de enfoque na coleta de dados.

\section{Questionários}

Os questionários utilizados para a constituição do corpus do ALiB compreendem questões especificamente dirigidas para a obtenção de fatos fônicos, inclusive de natureza prosódica (questionário fonético-fonológico$\mathrm{OFF}$ ), variantes lexicais (questionário semântico-lexical-QSL) ou de estruturas morfossintáticas (questionário morfossintático-OMS), ao lado de questões de pragmática $(\mathrm{QP})$, questões de natureza metalinguística $(\mathrm{OM})$, temas para discurso semidirigido (TDS) e texto para leitura. 
A estrutura das questões se distingue em função do objetivo de cada tipo de questionário, procurando-se obter, no $\mathrm{OFF}$, o registro de uma variante fônica em vocábulos selecionados; no QSL, variantes lexicais características da localidade, a partir do fornecimento dos semas pertinentes; no OMS, variantes morfossintáticas, em questões diretamente dirigidas ao fato ou passíveis de serem flagradas na descrição de uma gravura ou no relato feito pelo informante, como nos exemplos a seguir:

OFF 055 - NOITE - Quando fica tudo escuro e as pessoas vão dormir é a _ ?

OFF 056 - DIA - E depois da noite, o que é que vem?

QSL 154 - PRESÉPIO - No Natal, monta-se um grupo de figuras representando o nascimento do Menino Jesus. Como chamam isso?

OSL 158 - PAPAGAIO DE PAPEL / PIPA - Como se chama aqui o brinquedo feito de varetas cobertas de papel que se empina no vento por meio de uma linha?

OMS 027 - COMIGO / COM EU / MAIS EU - Quando alguém não quer tomar café sozinho, diz para convidar outra pessoa: "Ouer tomar café __?"

OMS 021 - COMPARATIVO DE GRANDE / PEQUENO - Essas duas casas (mostrando um desenho de duas casas, uma grande e outra pequena) têm o mesmo tamanho? A primeiro é como? E a segunda? Poderia comparar as duas casas em termos de tamanho?

OMS 046 - TER/HAVER em sentido existencial - Como era esta cidade antigamente, em termos de festas? Antigamente, esta cidade era mais desenvolvida? Por quê?

As quatro questões de pragmática procuram saber como um rapaz jovem, ao encontrar um objeto na rua, se dirige a outro jovem, do sexo masculino e do sexo feminino, ou a um indivíduo idoso, também dos dois sexos, para dizer-lhe que o objeto caiu de seu bolso.

As seis questões metalinguísticas indagam sobre o modo de falar local, as pessoas que, segundo o informante, "falam de modo diferente" na localidade e em outras áreas brasileiras, o falar de épocas anteriores, solicitando exemplos dessas variantes.

Nos temas para discurso semidirigido, o informante deve discorrer sobre uma experiência pessoal, comentar um programa de televisão, descrever sua atividade profissional ou relatar um fato de seu conhecimento.

Os inquéritos são totalmente gravados e cópias em DVDs são encaminhadas ao Arquivo Nacional do Projeto ALiB, sediado no Instituto de Letras da Universidade Federal da Bahia, onde se procede ao controle do feito e à catalogação dos registros. Resultam, todos eles, do trabalho de campo porque a documentação é integralmente coletada in loco, não importando as distâncias a serem vencidas. 


\section{A pesquisa de campo}

A pesquisa de campo tem de maneira muito forte e incisiva dois veios: o da busca dos dados científicos e o do contato humano que caracteriza o encontro investigador-pessoa investigada. Para um trabalho que segue as pegadas da metodologia geolinguística, essas duas trilhas têm um sentido muito particular. De um lado, permitem registrar informações dos diferenciados usos de uma língua, usos muitas vezes marcados pelo aspecto arcaizante, ou inovador, ou denunciador de certa interferência de grupos imigrantes, ou ainda indicador das mudanças que começam a ser processadas naquela língua. De outro lado, propiciam ouvir de viva voz - e esse é um dos muitos pontos positivos - in loco, no ambiente em que vive o falante, no seu próprio contexto, no calor humano do aparentemente neutro interrogatório linguístico, histórias, relatos, explicações que exibem o peso da sua inserção cultural e da sua inserção no mundo. Se uma entrevista aguça nos pesquisadores todas essas faces, 1.100 entrevistas feitas em todo o país - meta e ideário do Projeto ALiB —, despertarão muito mais.

Neste item, pois, faz-se uma reflexão sobre a pesquisa de campo desse projeto nacional, não para descrevê-la na sua inteireza, mas para pinçar pontos e aspectos que mostram como se tem realizado. Para isso, traz-se uma consideração de caráter geral que diz respeito ao processo de realização das entrevistas - a preparação para ida ao campo, as viagens, o contato com facilitadores do trabalho e a busca dos informantes - , a que se rotula de ida ao campo, e outra, de cunho particular, que se refere ao sentido acadêmico, social e humano da pesquisa dialetal, a que se denomina no campo.

\section{A ida ao campo}

A ida ao campo tem um antes, um durante e, necessariamente, um depois e, como afirmam Cardoso e Ferreira (1994, p.23):

A metodologia do trabalho dialetal — nada obstante reconhecer-se que o fazer é que ensina, o fazer é que dita o método - pode ter alguns passos definidos, no sentido de ordenar e proporcionar melhor rendimento da investigação e disciplinar a pesquisa.

A ida, pois, a um campo com $8.511 .000 \mathrm{~km}^{2}$, área do Brasil, tem particularidades muito próprias e no que se refere à preparação requer um conhecimento amplo, pelo menos, da realidade brasileira e uma disposição sem limites para observar, ver, sentir e reagir harmonicamente a cada situação com a qual se depara o investigador. Nessa preparação prévia à viagem estão, assim, o conhecimento pleno do instrumento de trabalho, os questionários; o estudo da área/localidades 
que serão percorridas; a previsão de material a ser levado, desde aqueles de caráter acadêmico-científico aos de proteção contra insetos da região; o contato com os facilitadores do trabalho, as pessoas às quais se recorre como auxiliares indispensáveis na busca de informantes e que se tornam os grandes "avalizadores" da pertinência e da seriedade do destino do material a ser recolhido.

Nessa primeira parte, trabalha-se junto com dados atualizados do IBGE, com informações das Prefeituras locais, das Secretarias de Educação dos Municípios, das Igrejas que atuam na área e, sobretudo, com aquele filão que se chama a rede de amizade e conhecimento que se vem construindo por meio dos alunos, de diferentes procedências, que têm passado pelas mãos dos que compõem a Equipe ALiB por todo o Brasil. A partir daí, enfrenta-se o deslocamento para atingir a grande meta — o ponto da rede ALiB a ser inquirido.

Tem-se conhecimento das distâncias que unem e separam os diferentes rincões do país, tem-se, também, clareza da precariedade, particularmente em algumas regiões, das vias e dos meios de transporte, e tem-se, pelo menos, a ideia de que a alguns lugares se chega por terra, a outros pelo ar, a outros pela água, a outros se conjugam meios, e, ao atingir-se a terra, se faz o deslocamento interno a pé, de taxi e, hoje, nos tão atuais, pelo menos no interior, mototaxis. Nesse caminhar, tem-se que vencer as distâncias que separam o inquiridor dos pontos a serem inquiridos, as dificuldades decorrentes das intempéries, que fogem, obviamente, ao controle dos investigadores, e enfrentar, não poucas vezes, a travessia por áreas de litígio de terras e de situações de questionamentos indígenas. Para exemplificar as distâncias vencidas, uma vez que não cabe aqui e agora a contabilidade final dos quilômetros percorridos pelo projeto ALiB, trazse o total atingido pelo Regional Mato Grosso do Sul, coordenado por Aparecida Negri Isquerdo, Diretora Científica do Projeto, responsável pela documentação em 26 pontos da rede que se distribuem por oito estados (Mato Grosso do Sul, Mato Grosso, Paraná, Roraima, Acre, Tocantins, Amazonas, Goiás, Espírito Santo): $51.150 \mathrm{~km}$. Esse número significa: uma volta e mais um quarto de volta em torno do nosso planeta, na circunferência da terra na altura do Equador, ou seja, na sua parte mais ampla, cuja extensão é de $40.075 \mathrm{~km}$.

Vencida a distância, a outra batalha diz respeito à localização de informante que preencha fielmente os critérios estabelecidos pela metodologia do Projeto e à obtenção do seu consentimento explícito de que concorda em ser entrevistado e em disponibilizar um pouco de seu tempo, do seu modo de pensar e, às vezes, até de seus sentimentos, para que se conheça mais e melhor o português do Brasil.

Pode parecer fácil, mas quem já foi ao campo sabe que nem sempre se consegue fazer convergirem todos os critérios numa pessoa, a pessoa ideal. Cumprida a missão, a volta do campo torna-se uma viagem prazerosa, com sabor de vitória. 


\section{No campo}

Ao lado das questões relativas ao processamento dos dados coletados, necessária se faz uma consideração sobre o sentido social e humano da pesquisa dialetal.

Em primeiro lugar, destacar o momento da primeira entrevista do ALiB, feita em Quirinópolis, Goiás, por Vanderci de Andrade Aguilera, Diretora Científica do Projeto, e as lembranças que relata. Eram os idos de junho de 2001, exatamente o dia $1^{\circ}$, quando se faz a primeira entrevista das 1.100 estabelecidas, assim descrita:

Na manhã do dia $1^{\circ}$ de junho de 2001, realizei a primeira entrevista do ALiB, junto ao R. (R.G.S.), de 29 anos, numa das salas do próprio Centro Social Urbano, em ambiente tranqüilo, poucas vezes interrompida pela intervenção de um ou outro funcionário desavisado de nossa presença naquele local. Mas, no decorrer da entrevista, eis que um caminhão de som ambulante passa a circular várias vezes pelos arredores, anunciando a grande liquidação da loja tal e... perturbando o meu trabalho. Essa entrevista foi identificada como 126/1, em que o numeral antes da barra significa o ponto linguístico Quirinópolis e o 1 após a barra identifica o informante masculino jovem. (AGUILERA, 2006, p.233).

Começavam, assim, as entrevistas do ALiB, e se pensava naquele então: "Foi feita a primeira, faltam 1.099!". Do que relata a inquiridora, no hotel, no seu primeiro café da manhã em Quirinópolis, vê-se que manteve conversa com a copeira, com a faxineira, com o gerente do hotel e todos se propõem a ajudá-la, a começar por ensinar-lhe o caminho para chegar à Prefeitura. Mantém contato com a coordenadora do Centro Social que se "[...] empolga com a minha exposição e já começa a fazer uma lista dos possíveis informantes" (AGUILERA, 2006, p.233). Uma primeira lição nos vem daí: a compreensão que pessoas totalmente desvinculadas de um trabalho dessa natureza são capazes de manifestar e, em decorrência, a capacidade de assumir o papel de coadjuvantes.

Na linha da compreensão do projeto, outro inquérito vem para ilustração. Fazia-se a documentação do informante faixa etária II, portanto dos 50 anos para cima, homem de escolaridade fundamental. Foi entrevistado na sala da sua casa, casa simples nos arredores de Recife, ato presenciado, além dos partícipes - o informante, a inquiridora e a auxiliar de pesquisa -, pela sua esposa. A documentação dos dados corria muito bem, acabava-se de fazer a aplicação do OFF, do QSL e do OMS — como se sabe, uma espécie de pingue-pongue em que o inquiridor pergunta e o informante responde - e passava-se às questões semidirigidas, nas quais se pede ao informante o relato de fatos sobre temas orientados. Naquele exato momento, se desgruda da sala a esposa do informante que volta, incontinente, com um sanduíche quente e um suco de laranja, e 
sussurra ao ouvido da inquiridora: "Estou vendo que agora é ele que fala mais e aí a senhora pode comer uma coisinha". Compreensão da pesquisa, respeito ao método, entendimento perfeito da mecânica do interrogatório linguístico, uma solidariedade ilimitada ao trabalho dialetal. É preciso que se diga: acabado o inquérito, ao entrarem no táxi inquiridora e auxiliar, aquela não pode conter as lágrimas da emoção seguradas no final da gravação.

São essas e outras lições que o trabalho de campo permite ao pesquisador aprender ou reafirmar o seu aprendizado.

\section{Estado atual}

Passando por todas essas etapas, o Projeto Atlas Linguístico do Brasil (ALiB) encontra-se, atualmente: (i) na fase final de levantamento de dados para constituição do corpus, tendo já alcançado a documentação de $93.6 \%$ das 250 localidades previstas com $94.2 \%$ dos 1.100 informantes programados, e contando com 20 estados onde a pesquisa foi integralmente realizada e se encontra concluída; e (ii) na etapa de análise dos dados, especialmente das capitais de Estado, com vistas à publicação de um primeiro volume de cartas, acompanhado de estudos sobre os fatos linguísticos objeto da cartografia. Ao lado disso, procedese à constituição de um Banco de Dados informatizado, que deverá permitir acesso aos dados e consulta ao atlas falante.

O Projeto ALiB chega ao estágio em que se encontra, presentemente, graças ao trabalho conjunto e coordenado do Comitê Nacional e das Equipes Regionais, estruturado sob a direção de membros do Comitê Nacional, que constituem o que já se convencionou chamar de Família ALiB. Para tanto, dois tipos de ação têm sido de fundamental importância: as reuniões do Comitê Nacional e os workshops nacionais.

As reuniões do Comitê Nacional, das quais a XXXV realizou-se em Salvador, em julho de 2012, por ocasião X Workshop do Projeto Atlas Linguístico do Brasil, têm um papel fundamental na condução do projeto. Por um lado, constituemse, inicialmente, em momentos de montagem do seu arcabouço, definição dos princípios que devem ser seguidos, articulação de políticas que lhe deem sustentabilidade, avaliação do andamento, análise de dados e preparação de materiais para publicação.

De não menor importância para a sustentação do projeto, está a realização de workshops nacionais, o último dos quais, o décimo, aconteceu em Salvador, no mês de julho de 2012. Os workshops se constituem em momentos de fundamental importância para o desenvolvimento do projeto, considerando-se que nesses encontros discutem-se a metodologia do trabalho, o andamento da pesquisa, 
os resultados de análises parciais e as atividades relacionadas à sustentação do trabalho; efetiva-se a discussão continuada da metodologia do trabalho, avaliando a sua aplicação e procedendo-se a reajustes, quando necessários e indicados pela experiência do trabalho de campo; são analisados os materiais reunidos e submetidos a estudo, buscando-se definir o quadro geral de fenômenos selecionados para informação sobre a realidade no território nacional.

Destaca-se que os três primeiros eventos destinaram-se à preparação de inquiridores para a execução dos 1.100 inquéritos linguísticos que deveriam recobrir 250 localidades, distribuídas de norte a sul do país. Convém assinalar que, sem extrapolar o número de participantes compatível com a natureza do trabalho a ser desenvolvido, tem-se facultado a participação nesses workshops a membros de equipes regionais envolvidas com a elaboração de atlas linguísticos de seus Estados e a pesquisadores interessados na temática.

\section{À guisa de conclusão}

O Atlas Linguístico do Brasil, proposto como se vem de apresentar, constituise em instrumento que nos revela a realidade do português brasileiro, mostra a diversidade de usos e a unidade a que é capaz de chegar a língua no Brasil. Em relação a resultados, os primeiros volumes do Atlas Linguístico do Brasil, referentes aos dados das capitais, deverão ser publicados em breve, espera-se que até 2012, com a apresentação de cartas fonéticas (inclusive prosódicas), morfossintáticas e lexicais, acompanhadas, como nos atlas ditos de $2^{\mathrm{a}}$ geração, dos comentários a cada uma delas, juntamente com o volume de Introdução.

Em versão preliminar, as análises que constituirão $01^{\circ}$ volume de cartas foram apresentadas no IX Workshop do Projeto ALiB, realizado no Instituto de Letras da UFBA, em julho de 2011, algumas das quais se passa a fazer uma breve referência a seguir.

Entre os dados fonético-fonológicos, cita-se a distribuição do $<\mathrm{S}>$ em coda silábica, como em estrada, casca, mesmo, desvio, três, arroz. Quanto a esse fato, os dados do ALiB referentes às capitais mostram, quanto à variação entre alveolares e palatais, áreas não contíguas, assim distribuidas: (i) áreas de predominância de variantes palatais, representadas, principalmente, por Rio de Janeiro, Belém e Florianópolis, mas onde se incluem, com índices menos elevados e, em alguns casos, restritos ao contexto medial, capitais do Norte (Macapá, Manaus, Boa Vista, Rio Branco e Porto Velho), do Nordeste (Recife, Salvador, Aracaju e Natal) e do Centro-Oeste (Cuiabá); (ii) áreas em que se documentam índices mais elevados de alveolares, destacando-se Porto Alegre e Curitiba, no Sul, as três capitais do Sudeste (Belo Horizonte, São Paulo e Vitória) e, no Centro-Oeste, Goiânia e Campo 
Grande. Ainda se incluem nesse grupo, embora com índices um pouco mais elevados de variantes palatais, no Nordeste, Teresina, Maceió, Fortaleza, João Pessoa e São Luís (MOTA; JESUS; EVANGELISTA, 2010).

No nível morfossintático, cita-se, para ilustração, o tratamento dado ao interlocutor na conversação em geral e numa mesma situação de discurso. Os dados revelam que há uma preferência acentuada pelo uso de você; no entanto observa-se a presença de áreas onde se registra a preferência ou a tendência para o uso de tu. Quanto a estas, destacam-se os seguintes aspectos: (i) uma área na qual o uso de tu se situa entre 77\%-97\% — Porto Alegre; (ii) uma outra área cuja presença de tu está entre 35\%-55\% — São Luís; e (iii) áreas nas quais se esboça uma presença de tu que se destaca das demais regiões, com índice entre 15\%-34\%, como se verifica nas capitais Rio Branco, Manaus, Macapá, Belém, Recife e Florianópolis.

No nível lexical, os estudos têm revelado uma significativa diversidade de usos. Por exemplo, a carta experimental galinha d'angola apresenta dez variantes para a identificação da ave: angola, angolista, capote, catraia, cocar, galinhola, guiné, picote, saquê, tô fraco. O levantamento e o estudo das formas demonstraram que, embora haja um número significativo de variantes, pode-se perceber uma distribuição uniforme para as regiões: (i) Norte: predominância da variante picote; (ii) Nordeste: predominância da variante guiné, coocorrendo com galinha d'angola; (iii) demais regiões: predominância de galinha d'angola.

Ao lado das análises dos dados das capitais com vistas à publicação do $1^{\circ}$ volume de cartas do ALiB, contam-se para a divulgação de resultados preliminares com estudos mais restritos, discutidos em reuniões científicas e publicados em Anais e periódicos da área pelas equipes responsáveis pelo ALiB, e com a realização de dissertações de Mestrado e teses de Doutorado, realizados sob a orientação de membros do Comitê Nacional.

CARDOSO, S. A.; MOTA, J. A. The project linguistic atlas of Brazil: antecedents and current stage. Alfa, São Paulo, v.56, n.3, p.845-860, 2012.

- ABSTRACT: This article deals with the Project Linguistic Atlas of Brazil, paying special attention to its antecedents which, in the history of Brazilian Geolinguistics, explain its appearance in 1996, by the time of the Ways and Perspectives for Brazilian Geolinguistics Seminar, held at the Federal University of Bahia, that counted on the participation of researchers of this field of knowledge, mainly authors of published and yet to be published atlases. The article presents information about the Project, its goals, how the field research has been done, the stage it is at, presently with 92,8\% of localities already researched, and the results that preliminary analyses have shown. Two aspects of its organization are evident: the regular meetings of the National Committee that coordinates the Project (the last one, numbered XXXIV, took place in February, 2012) and workshops for discussion, work assistance and the 
formation of inquirers and assistant researchers. From the methodological point of view, the Project belongs to the contemporary pluridimensional geolinguistics, and it prioritizes not only the diatopic variation, but also the diagenerational, diageneric and diastratic variation.

- KEYWORDS: Linguistic Atlas of Brazil. Geolinguistics. Diatopic variation. Linguistic variation.

\section{REFERÊNCIAS}

AGUILERA, V. de A. De Quirinópolis-GO: a entrevista nº 1 do ALiB. In: CARDOSO, S. A; MOTA, J. A. (Org.). Documentos 2: projeto Atlas Lingüístico do Brasil. Salvador: Quarteto, 2006. p.229-238.

Atlas Lingüístico do Paraná. Curitiba: Imprensa Oficial, 1994. v. I.

ARAGÃO, M. do S.; MENEZES, C. Atlas Lingüístico da Paraíba I-II. Brasília: Universidade Federal da Paraíba: CNPq, 1984.

BRASIL. Decreto n. ${ }^{\circ}$ 30.643, de 20 de março de 1952. Institui o Centro de Pesquisas da Casa de Rui Barbosa e dispõe sobre seu funcionamento. Diário Oficial da União, Brasília, 20 mar. 1952.

CARDOSO, S.; FERREIRA, C. A dialectologia no Brasil. São Paulo: Contexto, 1994. COMITÊ NACIONAL. Atlas Lingüístico do Brasil: questionários 2001. Londrina: Ed. da UEL, 2001.

Projeto Atlas Lingüístico do Brasil. Salvador: Instituto de Letras, 1998. Não publicado.

Projeto Atlas Lingüístico do Brasil. Salvador: Instituto de Letras, 2003. Não publicado.

CUNHA, C. F. da; SILVA NETO, S. da. Atlas Linguístico-Etnográfico do Brasil. In: COLÓOUIO INTERNACIONAL DE ESTUDOS LUSO-BRASILEIROS, 3., 1957, Lisboa. Actas... Lisboa: [S.1], 1960. v. II. p.405-412.

FERREIRA, C. et al. Atlas Lingüístico de Sergipe. Salvador: Universidade Federal da Bahia: Fundação Estadual de Cultura de Sergipe, 1987.

GILLIÉRON, J.; EDMONT, E. Atlas Linguistique de la France. Paris: Honoré Champion, 1902-1910.

KOCH,W.; KLASSMANN, M. S.; ALTENHOFEN, C. V. Atlas Lingüístico Etnográfico da Região Sul do Brasil (ALERS). Porto Alegre: UFRGS; Florianópolis: UFSC; Curitiba: UFPR, 2002. 2 v.

MOTA, J.; JESUS, C. de; EVANGELISTA, G. K. O <S> em coda silábica em capitais brasileiras: dados do projeto atlas linguístico do Brasil (ALiB). Estudos linguísticos e literários, Salvador, n.41, p.189-228, jan./jun.2010. 
NASCENTES, A. Bases para a elaboração do Atlas Lingüístico do Brasil. Rio de Janeiro: MEC: Casa de Rui Barbosa, 1958. v. I.

RIBEIRO, J. et al. Esboço de um atlas lingüístico de Minas Gerais. Rio de Janeiro: Fundação Casa de Rui Barbosa: Universidade Federal de Juiz de Fora, 1977. v. 1.

ROSSI, N.; CALLOU, D.; FERREIRA, C. Atlas prévio dos falares baianos. Rio de Janeiro: Ministério de Educação e Cultura - Instituto Nacional do Livro, 1963.

SILVA NETO, S. da. Guia para estudos dialectológicos. Belém: Conselho Nacional de Pesquisas - Instituto Nacional de Pesquisas da Amazônia, 1957.

THUN, H. Atlas linguistique et variabilité - introduction à la table ronde. In: CONGRESS INTERNATIONAL DE LINGUISTIOUE ET DE PHILOLOGIE ROMANES, 22., 1998, Bruxelles. Actes... Tübingen: Max Niemeyer, 2000. v. III. p.407-409.

Recebido em abril de 2012.

Aprovado em junho de 2012. 